\title{
Soy Isoflavones and Breast Cancer
}

\author{
Kevin McLaughlin, MA.SC., D.C ${ }^{1}$
}

\section{Introduction}

It has been recognized for several decades that the use of legumes in traditional eastern diets has played a significant role in the incidenceand mortality of certain disease states. Soy beans and products containing soy possess unique phytochemicals known as isoflavones which are thought to exert many biological effects in the human body.

Scientists have proposed that these unique isoflavones have hormonal influences which can interact with many different cell types producing varied physiological responses. Epidemiological data, human cell line studies, randomized trails and review articles have consistently shown that certain population groups (Asians, vegetarians) who regularly consume a soy-based diet are afforded protection from breast cancer, endometrial cancer, prostate cancer, heart disease, osteoporosis, and symptoms of hormonal deficiency. ${ }^{1}$ Typically, Japanese women have higher levels of circulating and urinary isoflavones compared to Western women with concomitant lower rates of hormone-dependent cancers. Japanese women also have lower rates of osteoporosis, heart disease and menopausal complaints.

Researchers have postulated that soy isoflavones may act as weak estrogen antagonists by influencing estrogenic metabolism and menstrual cycle length in premenopausal women but may concurrently act as weak estrogen agonists in postmenopausal women. Breast cancer has been associated with higher circulating levels of estradiol and prolactin with lower levels of progesterone. ${ }^{2}$ The proposition, therefore, has been made that soy isoflavones may modulate breast cancer risk in menopausal women but may also afford protection to the bones, cardiovascular and

1. 50 Main St. Commerce Court Building, Suite 11 Corner Brook, NF A2H 1 C9 central nervous systems required because of resulting estrogenic decline. ${ }^{3}$

It is also interesting to note that Asian immigrants who move to North America and consume the typical North American diet seem to quickly lose the protection that their diet once afforded them.

Since genetic factors account for only $10-15 \%$ of breast cancer cases, researchers are recognizing that environmental factors including nutrition may play a significant role in predisposing certain women to breast cancer. Studies of Asian women have indicated that a common possible mechanism of action for breast cancer protection may reside in the early, specific, nutritional exposure to the isoflavone genistein, the principle isoflavone found in soy. Certainly, higher levels of isoflavanoids found in healthy neonatal Japanese infants indicate transfer of isoflavones from the mother to the infant. This fact has led researchers to postulate that modification of estrogen metabolism from isoflavones may occur quite early and may also subsequently confer a lowered risk of cancer. ${ }^{4}$ Genistein has been reported to affect many biochemical pathways. It has, as previously mentioned, been associated with alteration in estrogen metabolism, inhibition of Topoisomerase 2, growth factor activity, malignant cell proliferation combined with induction of cell differentiation, antioxidant activity and antiangiogenesis. 5,6

\section{Soy Metabolism}

Soy isoflavones are heterocyclic phenols, structurally similar to 17-beta estradiol and are selective estrogen receptor modulators. Cellular mechanisms of action primarily depend upon the nature of the target tissue, receptor status, and level of endogenous hormones. ' Vegetarians have higher fecal weight and increased fecal excretion of estrogens. They also have lower rates of urinary excretion of estriol than 
omnivores. It is also interesting to note is that their plasma levels of estrone and estradiol are negatively correlated with fecal excretion of the same. These changes in estrogen metabolism are associated with the vegan diet typically higher in soy protein, fiber and lower in fat compared to the omnivore diet. 8

Studies looking at the changes in the Western vs. the Eastern diet have looked at the protein and fat as being the important nutritional factor in the difference in disease incidence. Certainly, diets low in methionine have been linked to decreased polyamine synthesis. Increased polyamine levels are believed to be necessary for tumor growth. ${ }^{9}$ However, Western diets typically contain low-levels of legumes which normally contain a variety of lignans and isoflavanoids deemed to be biologically active. Components of the vegan diet, such as higher fiber and isoflavone content are considered to be one of the most important factors in regulating potential disease activity. These factors may explain the differences in disease incidence between the two types of diets. ${ }^{10}$

There has been evidence concluding that Soy phytoestrogens, because of their unique metabolism, decrease the risk of developing various types of cancer. . $^{11-15}$

The majority of phytoestrogens found in the human diet may be classified as isoflavones and lignans. Isoflavones are structurally chemically similar to 17-beta estradiol, diethylstilbestrol and tamoxifen. The position of the $\mathrm{OH}$-group on soy phytoestrogen compounds and 17-beta estradiol give these compounds unique estrogenic activity at the receptor state. Phytoestrogens are a group of non-steroidal compounds that behave like estrogenic compounds. I soflavones compile the most common form of phytoestrogens. These unique chemicals also contain a phenolic ring structure that provides binding capability at estrogen receptor targets including the newly discovered ErB (Estrogen receptor Beta). This receptor is widely distributed in the brain, bones, bladder and vascular endothelial tissues.

In humans, the major isoflavones are genistein and daidzein which are metabolized from plant sources of biochanin A and formonentin. In plants, isoflavones are normally bound as glycosides but when hydrolyzed and fermented by intestinal bacteria, these compounds become activated and are absorbed as metabolites or as the parent compound (aglycone).The extent of microfloral activity has a profound impact upon bioavailability and physiological metabolism of I soflavones.In the intestinal tract, diadzein may be metabolized to equol or 0 -demethylangolensin and genistein can be metabolized to P-ethylphenol. These phytoestrogens are the major isoflavones found in human blood and urine.

Isoflavones are weakly estrogenic compounds $\left(10^{-2}-10^{-3}\right)$ compared to estradiol or estrone. Since these compounds have a preference for binding on the ErB receptor, this may indicatethat their biochemical influence may be exerted through a distinct pathway compared to endogenous estrogens. Phytoestrogens have a lower affinity for serum binding proteins which would potentially allow a greater volume of free isoflavone molecules to interact with tissue receptors. ${ }^{16}$

Studies have shown that there may be substantial variability in individual isoflavone metabolism. However, complete excretion of genistein and daidzein from the time of intake is complete within 24 hours. ${ }^{17}$ Soy beans contain the only relevant nutritional sources of isoflavones. Soy beans and soy products contain approximately 1-3 $\mathrm{mg}$ isoflavones per gram of protein. Other forms of soy products include, tofu, tempeh and soy milk. Miso and soy sauce also contain small amounts of isoflavones. Soy protein isolates contain approximately half of the phytoestrogens normally found in unprocessed soy beans. Soy protein can be 
consumed in various food stuffs including, soy protein isolate, baked goods, meat products and textured foods. The consumption of genistein in Asian population varies from $20-80 \mathrm{mg} /$ day. The typical diet consumed in the United States characteristically contains between $1-3 \mathrm{mg} /$ day. $^{18}$ One serving of soy food products from an Asian diet typically yields between 25-40 $\mathrm{mg}$ isoflavones per serving. Considering their low potency relative to endogenous estradiol, isoflavones are physiologically quite active as serum levels can exceed levels that which are normally experienced with endogenous estrogen production. In those consuming soy products, isoflavone concentration in blood can reach $6 \mathrm{mmol} / \mathrm{L}$. Japanese men characteristically have blood levels in the range of $300-400 \mathrm{nmol} / \mathrm{L}{ }^{18}$

After absorption from the gut, isoflavones are transported via the portal circulation to the liver where they are removed. However, some isoflavones can escape initial hepatic uptake and enter the peripheral circulation. The relative amount of isoflavones which can avoid hepatic clearance influences the amount which is able to interact with peripheral receptor sites. Isoflavones are principally excreted via the kidneys and gut in a similar manner as endogenous estrogen. ${ }^{19}$

Measurement of isoflavones typically utilizes HPLC (Higher Performance Liquid Chromatography). Excretion and plasma values vary upon dosage, type of product injested, gender, race and the metabolic activity of gut microflora. ${ }^{20-26}$

\section{Biological Mechanisms of Action}

Diets high in soy isoflavones, as previously described have shown diverse biochemical activity. Various mechanisms of action, particularly in asian females, have been proposed to explain the differences in breast cancer incidence. These include endogenous or environmental estrogenic antagonism, inhibition of tyrosine-kinasedependent signal transduction and cellu- lar antioxidant activity. It has been proposed that genistein may influence kinase enzymic expression, and may react with pro-oxidant hypochlorous acid readily expressed during the inflammatory reaction. ${ }^{27}$ Regulation of DNA topoisomerase activity, synthesis and release of Tumor Growth Factor Beta and induction of apoptosis of cancerous cells in vivo are other proposed mechanisms of activity. ${ }^{28,29}$

Cell cycle regulation of $\mathrm{P} 21$ is also known to be up-regulated by genistein and may play a significant role in determining the potential sensitivity of breast epithelial cells, normal or malignant to genistein..$^{30,31}$ Genistein has also been shown to inhibit topoisomerase 2 by inducing the upregulation of P53 protein, thus primarily providing stabilization of the DNA cleavage complex. ${ }^{32}$ There are numerous other studies which have shown positivealterations in tumor cell activity by various mechanisms in the presence of isoflavones in human and animal models. ${ }^{33-54}$

These in vitro studies are numerous and do indicate that genistein, daidzen and glycetin can influence breast cell tumor metabolism in a positive way. These studies are important because they can indicate the possible mechanism of action that isoflavones may exert at the cellular level. However, in vivo studies do reveal some important aspects of isoflavone activity which may have a more significant influence upon the incidence of breast cancer in women. It is known that breast cancer patients excrete small amounts of isoflavones (daidzen, genistein, glycetin, equol and 0 desmethylangolensin) relative to controls. Individuals in the highest tertile of isoflavone excretion have shown approximately $50 \%$ less breast cancer risk than those in the lowest tertile. ${ }^{55}$

As previously indicated, soy isoflavones have demonstrated steroid-like hormonal activity at the cellular level. Of all those tested, genistein and biochanin-A have shown the most significant estrogenic 
activity on human breast cancer cells compared to estradiol, dihydrotestosterone and synthetic progesterone. ${ }^{56}$

Studies evaluating isoflavone activity at the receptor site have shown some interesting findings. Genistein can induce the down-regulation of ER-alpha messenger RNA. It has also been shown that genistein possesses estrogenic, agonistic activity at both ER alpha and ER beta receptor sites. Depending upon the dosage, genistein has been shown to either stimulate ER alpha-dependent breast cancer cell lines or demonstrate cytotoxic activity. ${ }^{57}$ It has been also demonstrated that the binding affinities of genistein and equol are comparable to the binding affinity of 17 beta estradiol. Although the binding affinities are equal, cell growth due to gene expression involving estradiol is double to that of genistein. It has also been demonstrated that genistin, the conjugated (Bglycoside) form, binds with less affinity than genistein but stimulates breast cancer cell growth to a greater extent. ${ }^{58}$

Isoflavones have also been shown to influence the menstrual cycle in various populations of women. In one study of premenopausal women, isoflavones prolonged menstruation in $60 \%$ of the subjects. Some subjects showed lower levels of 17-Beta estradiol, and increased levels of sex hormone binding globulin. Other hormones such as androstenidione, testosterone and DEAS demonstrated variable responses depending upon the phase of menstruation (luteal vs. follicular). Levels of T3 and T4 also changed after isoflavone administration, increasing in the follicular phase with a subsequent decrease in the luteal phase. Thus it has been postulated that isoflavones may influence metabolic activity at higher centers including the hypothalamopituitary-gonadal axis. ${ }^{59}$ Other studies have shown lower levels of 17-beta estradiol in women following administration of Isoflavones resulting in favorable changes in hormonal metabolism or significant, equally positive alterations in menstrual cycle length. .0.72 $^{-72}$

\section{Conflicting Evidence}

The consumption of soy foods high in isoflavones has occasionally been scrutinized because soy isoflavones can exert estrogenic activity in breast cancer cells. Thus, the role of soy as a preventative measure for possible breast cancer development has subsequently been challenged.

Firstly, there is some evidence that soy isoflavones have shown no influence in premenopausal female menstrual cycle length or hormonal profile in subjects taking oral contraceptives verses those not taking oral contraceptives. ${ }^{73}$ However, in this study the dosage of isoflavones was only $38 \mathrm{mg}$., and feeding only occurred for 2 months. There was no control group, nor were other aspects of diet or lifestyle controlled.

Another study indicated that isoflavones are not likely to exert their influence primarily by altering menstrual cycle characteristics or hormonal metabolism in premenopausal women.This study also had design flaws and had a low number of subjects (14)..$^{74}$ Other studies have shown that genistein can stimulate estrogen-dependent breast cancer cells in athymic mice in a dosedependent manner. Expression of PS2 was greater in the tumors from the group consuming the highest amount of genistein..$^{75,76}$ Although 17-B-estradiol can produce a similar effect but in a greater capacity, concern has been raised whether the results of this experimental model can be extrapolated to pre- or postmenopausal women. It has also been mentioned that in experiments looking at mice treated with 17-B estradiol, genistein significantly inhibited breast cancer growth in vivo. In one particular study, $60 \mathrm{~g}$ of soy protein containing $45 \mathrm{mg}$ of isoflavones consumed for 2 weeks stimulated DNA synthesis in healthy breast cells examined after biopsy using pre-menopausal women with benign and malignant breast disease. ${ }^{77}$ This study 
has received criticism because it only assessed cell growth, not apoptosis. It's length is also rather controversial (2 weeks), as chronic exposure of isoflavones downregulates the estrogen receptor. Assuming down-regulation takes greater than 2 weeks to occur, the effect upon cell proferation would not have been shown in this case. Also, the increase in the follicular phase length of the menstrual cycle in response to soy feeding, would not be apparent after 2 weeks of soy injestion. Although as previously mentioned, some studies have shown no effect with soy and menstrual cycle length or estrogen metabolism, other work has shown a positive influence in estrogen metabolism in pre-menopausal women. The urinary ratio of 2 to 16 alpha hydroxylated estrogens and 2 to 4 hydroxylated estrogens was increased. This is considered protective for breast cancer development because these estrogenic metabolites are excreted, which would otherwise affect breast cellular growth to a greater degree. Other studies with monkeys have shown that soy feeding antagonized the mammary cellular growth perpetuated by estradiol.

Genistein has also been shown to reduce chemically induced mammary cancer in neonatal or prepubertal rats later in their lives.The postulated mechanism may involve genistein's ability to enhance breast cell development and differentiation which offers protection in adulthood. ${ }^{78}$ Studies have also indicated that feedings comparing various types of proteins especially, Soy protein isolate can positively affect estrogen metabolism (reduce 17-Beta estradiol) and reduce the incidence of chemically-induced mammary cancer in mice. ${ }^{79}$ Another study has indicated that prolonged consumption of soy protein isolate may have a stimulatory effect ( $30 \%$ of subjects) on premenopausal breast secretion, the appearance of hyperplastic cells following aspirate and erratic elevation in plasma estradiol levels. ${ }^{80}$ Another study lasting only two weeks also showed increased breast fluid aspirate and PS2 expression, but no influence upon cell growth, hormonal metabolism or cell mitosis in healthy premenopausal women. ${ }^{81}$

\section{Conclusions}

Although some of the data indicate some discrepancy, there are issues of experimental design, variable isoflavone content of products and the relevancy of extrapolated results to the human population in general, which are necessary to explore. The age-adjusted breast cancer death per 100,000 people is 27.4 in the USA and 6.7 in Japan. Soy isoflavones are powerful chemicals which have obviously affected breast cancer incidence and mortality in these populations of women.

Researchers at Wake Forest School of Medicine fed a soy protein diet to macaque monkeys (150 mg soy isoflavones/ day) for 3 years. No stimulation of breast or endometrial cells were observed. ${ }^{82} \mathrm{Dr}$ Anne Wu at the University of Southern California recently presented some early results of an unpublished human study at the American Institute for Cancer Research's 9th Annual Research Conference. In an on-going, casecontrol study involving 1200 subjects with 1200 controls investigating the use of soy and breast cancer risk, early data indicates that the consumption of soy-based food is associated with a significant reduction in breast cancer risk. Other human studies have indicated the same results..$^{83}$

Soy isoflavones lower breast cancer risk by many biochemical mechanisms. Some authors have suggested that soy products be given priority in clinical trails involving long-term adjuvant dietary treatment for early breast cancer patients. ${ }^{84}$ A nother author has indicated that although several studies in premenopausal women have suggested estrogenic activity on breast tissue, recently conducted studies lasting one year have indicated that isoflavones do not affect breast tissue density in pre- 
menopausal women and may decrease cellular density in postmenopausal women. The same author has also suggested that hormone replacement therapy, especially synthetic progestin may increase the risk of breast cancer.

It has been reasoned that since the data does not support the notion that soy affects the risk of developing breast cancer or is yet to show that it affects survival in breast cancer patients, it would seem unfounded to not recommend its use. ${ }^{85}$

\section{Future Considerations}

Presently, there is no known cause for sporatic breast cancer. As previously described, certain factors including, diet and environment may account for $70 \%$ of newly diagnosed breast cancer cases. Certainly, soy isoflavones can affect breast cancer risk, depending upon time and length of exposure. Early exposure may influence early epithelial breast cell differentiation, reduce the presence of ER alpha and increase the levels of ER-beta ( this is considered protective). ${ }^{86}$

If one considers the epidemiological data from studies assessing the health of asian women, theabsence of obvious harmful effects of a diet rich in soy is compelling. Indeed, their low rates of breast cancer and other disease is an argument to encourage women living in western communities to adopt the same type of diet.

The use of soy in place of HRT in patients whose use is contraindicated (breast cancer) presents a challenging question. The effect genistein exerts on the breast is dependent upon concentration level, levels of breast tissue estradiol and individual tissue metabolism. Some data indicates that the use of a weak estrogenic compound may be harmful in patients with hormonedependent breast cancer during the stage of micrometastasis. This, however is based on the premise that isoflavones may compete with tamoxifen and negate its effectiveness.
Since tamoxifen and genistein have similar binding affinities to ER alpha, genistein may displace tamoxifen, thus influencing its inhibitory effect. ${ }^{87}$ However, genistein has a strong affinity for the ER beta receptor which may discourage excessive activity at ER alpha. At high doses, tamoxifen and genistein exert synergistic, anti-proliferative breast cellular activity. Obviously, more study is required to determine whether soy isoflavones in the presence or absence of tamoxifen may have expanded importance in the adjunctive care of breast cancer patients.

With the use of a new, sophisticated breast imaging modality, researchers have confirmed the ability of soy protein to reduce inflammation in breast tissue. The preliminary results of the study utilizing the Breast Enhanced Scintigraphy Test (BEST) was presented at the International Symposium on the Role of Soy in Preventing and Treating Chronic disease, November, 2001. The BEST imaging yields diagnostic information about myocardial function and can distinguish normal breast tissue from that which contains inflammation or carcinoma. Compared to mammography, BEST correctly identifies cancer with a $100 \%$ reliability in over 70 patients. M ammography is at best $85 \%$ accurate. BEST also allows health care providers to diagnose breast cancer at an earlier stage.

The BEST imaging was used on 147 women and 3 men previously diagnosed with breast cancer over a 30 month period. There were 87 cases of women with inflammatory breast tissue (maximal count activity of $229+50$ ) of these 87 women, 40 were given $20 \mathrm{~g}$ of soy protein containing $160 \mathrm{mg}$ of soy isoflavones per day. Of the 40 women, 25 have been studied before and after six months of soy protein consumption. According to the lead researcher, Dr. Richard Fleming, there is a significant reduction in breast inflammation without cancerous recurrence (the resultant M.C.A. was $112 \AA 31$ ). An additional 15 women are 
currently being studied to ascertain if this effect will be persistent in the remainder of the experimental group. ${ }^{88}$

In another ongoing study conducted by Dr. William Dooley at John's Hopkins Breast Cancer Center, postmenopausal breast cancer survivors are being given soy protein, to alleviate the symptoms of hormonal deficiency. This study involves several hundred breast cancer patients in a multicenter, randomized, double-blind, placebo-controlled trial with the results hopefully being availablein a few months. Dooley is also involved in another study examining the effects of soy protein upon breast cancer cells in vivo. Newly diagnosed breast cancer patients will receive soy protein isolate daily up until surgery. Following the surgery, comparison will be made between the original biopsy specimen and the surgical specimen.

Sophisticated histological investigation including ductoscopy will assess cellular changes caused by the addition of soy to the diets of these patients. In Seattle, Washington, a study which began in $\mathrm{M}$ arch, 2001, researchers will examine the effect of soy protein isolate upon the urinary excretion of soy isoflavones in 400 women. Researchers will measure the amount and types of soy isoflavones and isoflavone metabolites excreted by women over a 3-day period. These urinary products will be compared with those previously found to be associated with lower rates of breast cancer.

The value of soy in women's health can be realized if one considers that soy can behave as an anti-estrogenic substance in premenopausal women by reducing signs and symptoms of estrogen dominance (breast tenderness, cystic changes) or it may exert mild estrogenic activity in postmenopausal women to alleviate vaso-motor symptoms (hot flushes, might sweats) associated with estrogen deficiency.

Since soy is approximately 1000 times weaker than estradiol and 3000 times weaker than Premarin; but has few sideeffects like those associated with tamoxifen, it may bethe food of choicefor most women. Soy, with its synergistic matrix of phytochemicals positively exerts an adaptogenic influence upon the female hormonal milieu. From a preventive aspect, soy has been shown to provide meaningful physiological benefits to the skeletal, cardiovascular and central nervous systems of women.

A recently discovered class of soy nutrients, distinct from soy isoflavones may have potent antiestrogenic activity upon receptors in breast tissue. Researchers have noted a strong antiestrogenic effect of glyceollins on estrogen receptor signaling which ultimately suppresses estrogeninduced proliferation of breast cancer cells. ${ }^{89}$ It would appear that soy may seem to exert its fullest physiological potential when consumed as a whole protein supplement as opposed to an extracted isoflavone capsule.

It may be interesting to note that on April 20, 1999 a patent was submitted by Taylor et al in the United States involving a compound composed of a combination of the known selective estrogen receptor modulators (raloxifene, droloxofene, toremifene, etc.), co-administered with at least one isoflavone selected from genistein, daidzein, biochanin A, or formonetin. This compound has the intent to prevent, minimize or reverse the development and growth of breast cancer. It seems clear from this patent application submitted by Protein Technologies International Inc., that soy isoflavones are being combined with pharmaceuticals to produce beneficial physiological synergy in vivo. Obviously, the results of previous studies which have evaluated the synergism between Tamoxifen and soy isoflavones indicating the downregulation of signal transduction in breast cancer cells have had a positive influence upon the potential development of a new class of experimental chemicals which, potentially may beutilized in the adjunctive care of breast cancer patients..$^{90}$ 


\section{References}

1. Knight DC, Eden JA: A Review of the Clinical effects of Phytoestrogens, Obstet Gynecol, 1996, May; 87 (5 pt 2): 897-904

2. Meyer F, Brown JB, Morrison AS, M acM ahon B: Endogenous sex hormones, prolactin, and breast cancer in premenopausal women, J Natl Cancer Inst, 1986, Sep; 77(3): 613-6.

3. Mindy S, Kurzer: Hormonal Effects of Soy Isoflavones: Studies in Premenopausal and Postmenopausal Women, J Nutr, 2000;130:660S-6615).

4. Adkercreutz $\mathrm{H}$, Yamada T, Wahala K, Watanabe S.Maternal and neonatal phytoestrogens in Japanese women during birth, Am J Obstet Gynecol, 1999, M ar; 180 (3 pt 1): 737-43.

5. Adlercreutz $\mathrm{H}$ : Phytoestrogens: epidemiology and a possible role in cancer protection, Environ Health Perspect, 1995, Oct; 103 Suppl 7: 103-12.

6. Lamartiniere CA: Protection against breast cancer with genistein : a component of soy. Am J Clin Nutr, 2000, Jun; 71 (6 Suppl): 1705S-7S; discussion 1708S-9S.

7. Vincent $A$, Fitzpatrick, LA: Soy isoflavones: are they useful in menopause? Mayo Clin Proc, 2000, Nov; 75 (11):1174-84.

8. Goldin BR, Adlercreutz H, Gorbach SL et al: Estrogen excretion patterns and plasma levels in vegetarian and omnivorous women. $\mathrm{N}$ Engl J Med, 1982, Dec 16; 307(25): 1542-7.

9. Cline JM, Hughes $C L$, Jr.Phytochemicals for the prevention of breast and endometrial cancer. Cancer Treat Res, 1998; 94:107-34.

10. Stephens FO.Breast cancer: aetiological factors and associations (a possible protective role of phytoestrogens). Aust N Z J Surg, 1997, Nov; 67 (11): 755-60.

11. Adlercreutz CH, Goldin BR, Gorbach SL et al: Soybean phytoestrogen intakeand cancer risk, J Nutr, 1995, Mar; 125 (3 Suppl): 757S-770S.

12. Ingram D, Sanders K, Kolybaba M, Lopez D: Case-control study of phyto-estrogens and breast cancer, Lancet, 1997, Oct 4; 350 (9083): 990-4.

13.Bradlow HL, Telang NT, Sepkovic DW, Osborne MP. Phytochemcials as modulators of cancer risk. Adv Exp Med Biol, 1999; 472: 207-21.

14. Kurzer MS, XuX:Dietary phytoestrogens. Annu Rev Nutr, 1997; 17: 353-81.

15. Bland JS: Phytonutrition, phytotherapy, and phytopharmacology. Altern Ther Health Med, 1996; Nov 2(6): 73-6.

17. Kenneth DR Setchell: Phytoestrogens: the biochemistry, physiology, and implications for human health of soy isoflavones, Am J Clin Nutr.1998; 68(suppl): 1333S-46S.
16. Than DM , Christopher D, Gardner WL, Haskell: Potential Health Benefits of Dietary Phytoestrogens: A Review of the Clinical, Epidemiological, and M echanistic Evidence. J Clin Endocrinol Metab, 83/ 7 2235; Copyright 1998 by the Endocrine Society.

18. Mark J: Messina.Legumes and soybeans: overview of their nutritional profiles and health effects. Am J Clin Nutr, 19990;70/3: 439S-450S.

19.Soyl soflavones.M onograph.http:// www. thorne.com/altmedrev/soy3-5.html.

20. Xu X, Harris KS, Wang HJ, Murphy PA, Hendrich S: Bioavailability of soybean isoflavones depends upon gut microflora in women. J Nutr, 1995, Sep; 125(9): 2307-15.

21. Setchell KD, Brown NM, Desai $P$ et al: Bioavail-ability of pure isoflavones in healthy humans and analysis of commercial soy isoflavones supplements.J Nutr, 2001, 4/ 131(4 Suppl): 1362S-75S.

22.Wiseman $\mathrm{H}$ : The therapeutic potential of phytoestrogens. Expert Opin Investing Drugs, 2000; Aug; 9(8): 1829-40.

23. Singletary K, Faller J, Li JY, M ahungu S: Effect of extrusion on isoflavone content and antiproliferativebioactivity of soy/ corn mixtures. J Agric Food Chem, 2000, Aug; 48(8): 3566-71.

24. Chen Z, Zheng W, Custer LJ, Dai Q, Shu XO, Jin $F$, FrankeAA: Usual dietary consumption of soy foods and its correlation with the excretion rate of isoflavonoids in overnight urine samples among Chinesewomen in Shanghai. Nutr Cancer, 1999; 33(1):82-7.

25. Maskarinec $G$, Singh S, Meng L, Franke AA: Dietary soy intake and urinary isoflavone excretion among women from a multiethnic population. Cancer Epidemiol Biomarkers Prev, 1998; Jul; 7(7): 613-9.

26. Barnes S, Sfakianos J, Coward L, Kirk M: Soy isoflavonoids and cancer preventions. Underlying biochemicals and pharmacological issues. Adv Exp Med Biol, 1996; 401: 87-100.

27. Barnes S, Boersma B, Patel R, et al: Isoflavonoids and chronic disease: mechanisms of action. Biofactors, 2000; 12(1-4): 209-15.

28. Boersma BJ, Barnes S, Kirk M, Wang CC, Smith M, Kim H, Xu J, Patel R, Darley-Usmar VM.Soy isoflavonoids and cancer- metabolism at thetarget site. Mutat Res, 2001; Sep 1; 480-481: 121-7.

29. Katdare M, Osborne MP, Teland NT. Inhibition of aberrant proliferation and induction of apoptosis in pre-neoplastic human mammary epithelial cells by natural phytochemicals. Oncol Rep, 1998; M ar-A pr; 5(2): 311-5.

30. Upadhyay S, Neburi M, Chinni SR, Alhasan S, Miller F, Sarkar FH: Differential sensitivity of normal and malignant breast epithelial cells to 
genistein is partly mediated by p21 (W AF1). Clin Cancer Res, 2001; Jun; 7(6): 1782-9.

31. Frey RS, Li J, Singletary KW: Effects of genistein on cell proliferation and cell cycle arrest nonneoplastic human mammary epithelial cells: involvement of Cdc2, p21 (waf/cip1), p27 kip1), and $\mathrm{Cdc} 25 \mathrm{C}$ expression. Biochem Pharmacol, 2001; A pr 15; 61(8); 979-89.

32. Ye R, Bodero A, Zhou BB, Khanna KK, Lavin M f, Lees-Miller SP: The plant isoflavenoid genistein activities p53 and Chk2 in an ATM dependent manner. J Biol Chem, 2001, Feb 16; 276(7): 4828-33.

33. Leung LK, Wang TT: $\mathrm{BCl}-2$ is not reduced in the death of MCF-7 cells at low genistein concentration, J Nutr, 2000; Dec; 130 (12): 2922-6.

34. Ohta T, Nakatsugi S, Watanabe K, et al: Inhibitory effects of Bifidobacterium-fermented soy milk on 2-amino-1-methyl-6-phenylimi-dazo 4,5-b pyridine-induced rat mammary carcinogenesis, with a partial contribution of its component isoflavones. Carcinogenesis, 2000; May; 21 (5): 937-41.

35. Nakagawa $H$, Yamamoto D, Kiyozuka $Y$, Tsuta K, Uemura Y, Hioki K, Tsutsui Y, Tsbura A.Effects of genistein and synergistic action in combination with eicosapentaenoic acid on the growth of breast cancer cell lines, J Cancer Res Clin Oncol, 2000; Aug; 126(8): 448-54.

36. Zaizen Y, Higuchi Y, Matsuo N, et al: Antitumor effects of soybean hypocotyls and soybeans on the mammary tumor induction by $\mathrm{N}$-methyl$\mathrm{n}$-nitrosourea in $\mathrm{F} 344$ rats. Anticancer Res, 2000; May-Jun; 20(3A): 1439-44.

37. Nakagawa $H$, Yamamoto $D$, Kiyozuka $Y$, tsuta K, Uemura Y, Hioki K, Tsutsui Y, Tsubura A: Effects of genistein and synergistic action in combination with eicosapentaenoic acid on the growth of breast cancer cell lines. J Cancer Res Clin Oncol, 2000; Aug; 126(8): 448-54.

38. Shao ZM, Shen ZZ, Fontana JA, Barsky SH: Genistein's "ER-dependent and independent" actions are mediated through ER pathways in ER-positive breast carcinoma cell lines. Anticancer Res, 2000; Jul-Aug; 20(4): 2409-16.

39. Li Y, Upadhyay S, Bhuiyan M, Sarkar FH Induction of apoptosis in breast cancer cells MDAM B-231by genistein. Oncogene, 1999; M ay 20; 18(20): 3166-72.

40. Appelt LC, Reicks M M : Soy induces phase II enzymes but dies not inhibit dimethyibenz a anthracene-induced carcinogenesis in female rats. J Nutr, 1999; Oct: 129(10): 1820-6.

41. Li Y, Bhuiyan M, Sarkar FH: Induction of apoptosis and inhibition of c-erbB-2 in MDAM B-435 cells by genistein. Int J Oncol, 1999; Sep; 15(3): 525-33.
42. Kim H, Peterson TG, Barnes S: Mechanisms of action of the soy isoflavone genistein: emerging role for its effects via transforming growth factor beta signaling pathways. Am J Clin Nutr, 1998; Dec; 68 (6 Suppl): 1418S-1425S.

43. Lamartiniere CA, Ahang JX, Cotroneo MS: genistein studies in rats: potential for breast cancer prevention and reproductive and development toxicity. Am J Clin Nutr, 1998; Dec; 68(6 suppl): 1400S-1405S.

44. Shao ZM, Wu J, Shen ZZ, Barsky SH : genistein exerts multiple suppressive effects on human breast carcinoma cells. Cancer Res, 1998; Nov 1; 58(21): 4851-7.

45. Verma SP, Goldin BR: Effect of soy-derived isoflavonoids on the induced growth of M CF-7 cells by estrogenic environmental chemicals, Nutr Cancer, 1998; 30(3): 232-9.

46. Gotoh T, Yamada K, Yin H, Ito A, Kataoka T, Dohi K: Chemoprevention of $\mathrm{N}$-nitroso- $\mathrm{N}$ methylurea-induced rat mammary carcinogenesis by soy foods or biochanih. A. Jpn J Cancer Res, 1998; Feb; 89(2): 137-42.

47.Barnes S: Thechemopreventive properties of soy isoflavonoids in animal models of breast cancer. Breast Cancer Res Treat, 1997; Nov-Dec; 46(2-3): 169-79.

48. Lamartiniere CA, Murrill WB, Manzolillo PA, et al: genistein alters the ontogeny of mammary gland development and protects against chemically-induced mammary cancer in rats. Proc Soc Exp Biol M ed, 1998; M ar; 217(3): 35864.

49. Peterson G, Barnes S: genistein inhibits both estrogen and growth factor-stimulated proliferation of human breast cancer cells. Cell Growth Differ, 1996; Oct; 7(10): 1345-51.

50. Lamartiniere CA, Moore JB, Brown NM, et al: genistein suppresses mammary cancer in rats, Carcinogenesis. 1995; Nov; 16(11): 2833-40.

51. Barnes S: Effect of genistein on the vitro and in vivo models of cancer. J Nutr, 1995; M ar; 125(3 Suppl): 777S-783S.

52. Lamartiniere CA, Moore J, Holland M, Barnes $S$ : Neonatal genistein chemo prevents mammmary cancer. Proc Soc Exp Biol Med, 1995; Jan; 208(1): 120-3.

53.Dixon-Shanies D, Shaikh N: Growth inhibition of human breast cancer cells by herbs and phytoestrogens. Oncol Rep, 1999; Nov-Dec; 6(6): 1383-7.

54.Pagliacci MC, Smacchia M, Migliorati G, Grignani F, Riccardi C, Nicoletti I: Growth-inhibitory effects of the natural phyto-oestrogen genistein in M CF-7 human breast cancer cells. Eur J Cancer, 1994; 30A(11):1675-82.

55. Zheng W, Dai Q, Custer LJ, et al: Urinary excre- 
tion of isoflavonoids and the risk of breast cancer, Cancer Epidemiol Biomarkers Prev, 1999; Jan; 8(1): 35-40.

56. Zand RS, Jenkins DJ, Diamandis EP: Steroid hormone activity of flavonoids and related compounds, Breast Cancer Res Treat, 2000 Jul; 62(1): 35-49.

57. Maggiolini $M$, Bonofiglio D, Marsico $S$, et al: Estrogen receptor alpha mediates the prolifertive but not the cytotoxic dose-dependent effects of two major phytoestrogens on human breast cancer cells, Mol Pharmacol, 2001, Sep; 60(3): 595-602.

58. M orito K, Hirose T, Kinjo J, et al: Interaction of phytoestrogens with estrogen receptors al phaand beta. Biol Pharm Bull, 2001; Apr. 24(4): 351-6.

59.Watanabe S, Terashima K, Sato Y, Arai S, Eboshida A: Effects of isoflavonesupplement on healthy women. Biofactors, 2000; 12(1-4): 233-41.

60. Nagata C, Kabuto M, Kurisu Y, Shimizu H: Decreased serum estradiol concentration associated with high dietary intake of soy products in premenopausal Japanese women, Nutr Cancer, 1997; 29(3): 228-33.

61. Lu LJ, Anderson KE, Grady JJ, Nagamani M : Effects of soy consumption for one month on steroid hormones in premenopausal women: implications for breast cancer risk reduction, Cancer Epidemiol Biomarkers Prev, 1996; Jan; 5(1): 63-70.

62. Cassidy A, Bingham S, Setchell K: Biological effects of isoflavones in young women; importance of the chemical composition of soybean products, Br J Nutr, 1995; Oct 74(4): 587-601.

63. Duncan AM, Underhill KE, Xu X, Lavalleur J, Phipps WR, Kurzer MS: Modest hormonal effects of soy isoflavones in postmenopausal women. J Clin Endocrinol Metab, 1999; Oct; 84(10): 3479-84.

64. Xu X, Ducan AM, Merz BE, Kurzer MS.Effects of soy isoflavones on estrogen and phytoestrogen metabolism in premenopausal women. Cancer Epidemiol Biomarkers Prev, 1998; Dec 7(12): 1101-8.

65. Lu LJ, Anderson KE, Grady JJ, Nagamani M : Effects of an isoflavone-free soy diet on ovarian hormones in premenopausal women. J Clin Endocrinol Metab, 2001; Jul; 86(7): 3045-52.

66. Pino AM, Valladares LE, Palma MA, M ancilla AM, Yanez M, Albala C: Dietary isoflavones affect sex hormone-binding globulin levels in premenopausal women. J Clin Endocrinol Metab, 2000: Aug; 85(8): 2797-800.

67. Lu LJ, Cree M, Josyula S, Nagamani M, Grady JJ, Anderson KE.Increased urinary excretion of 2hydroxyestrone but not 16alpha-hydroxyestrone in premenopausal women during a soya diet containing isoflavones. Cancer Res, 2000; $M$ ar 1; 60(5): 1299-305.

68. Duncan AM, Merz-Demlow BE, Xu X, Phipps WR, Kurzer M S: Premenopausal equol excretors show plasma hormone profiles associated with lowered risk of breast cancer, Cancer Epidemiol Biomarkers Prev, 2000; Jun; 9(6): 581-6.

69. Lu LJ, Anderson KE, Grady JJ, Nagamani M : Effects of an isoflavone-free soy diet on ovarian hormones in premenopausal women. J Clin Endocrinol Metab, 2001; Jul; 86(7): 3405-52.

70. Cassidy A, Bingham S, Setchell KD: Biological effects of a diet of soy protein rich in isoflavones on the menstrual cycle of premenopausal women. Am J Clin Nutr. 1994; Sep; 60(3): 333-40.

71. Nagata C, Takatsuka N, Inhaba S, Kawakami $\mathrm{N}$, Shimizu H: Effect of soymilk consumption on serum estrogen concentrations in premenopausal Japanese women. J Natl Cancer Inst, 1998; Dec 2; 90(23):1830-5.

72. Xu X, Duncan AM, Wangen KE, Kurzer M S: Soy consumption alters endogenous estrogen metabolism in postmenopausal women. Cancer Epidemiol Biomarkers Prev, 2000; Aug; 9(8): 781-6.

73. M artini MC, Dancisak BB, Haggans CJ, Thomas W, Slavin JL: Effects of soy intake on sex hormone metabolism in premenopausal women, Nutr Cancer, 1999; 34(2):133-9.

74. Ducan AM, Merz BE, Xu X, Nagel TC, Phipps WR, Kurzer MS: Soy isoflavones exert modest hormonal effects in premenopausal women. J Clin Endocrinol Metab, 1999; Jan; (1):192-7.

75. Allred CD, Allred KF, Ju YH, Virant SM, Helferich WG: Soy diets containing varying amounts of genistein stimulate growth of estrogen-dependent (M CF-7) tumorsin a dosedependent manner. Cancer Res, 2001; Jul1; 61(13):5045-50.

76. Hsieh CY, Santell RC, Haslam SZ, Helferich WG: Estrogenic effects of genistein on the growth of estrogen receptor-positive human breast cancer (M CF-7) cells in vitro and in vivo. Cancer Res, 1998; 1; 58(17): 3833-8.

77. McM ichael-Phillips DF, Harding C, M orton $M$, et al: Effects of soy-protein supplementation on epithelial proliferation in the histologically normal human breast. Am J Clin Nutr, 1998; 68(6 Suppl): 1431S-1435S.

78. Mark Messina: Soy, soy phytoestrogens (isoflavones), and breast cancer. Am J Clin Nutr. 1999; 70, No.4, 574-575.

79. Badger TM , Ronis M J, Hakkak R: Development effects and health aspects of soy protein isolate, casein, and whey in male and female rats, Int J Toxicol, 2001; M ay-Jun; 20(3): 165-74.

80. Petrakis NL, Barnes S, King EB. et al: Stimula- 
tory influence of soy protein isolate on breast secretion in pre- and postmenopausal women, Cancer Epidemiol Biomarkers Prev, 1996; Oct 5(10): 785-94.

81. Hargreaves DF, Potten CS, Harding C, et al: Two-week di etary soy supplementation has an estrogenic effect on normal premenopausal breast. J Clin Endocrinol M etab, 1999; Nov; 84 (11): 4017-24.

82-83. Breast Health: Can soy protein help maintain healthier breast tissues? http://www. health revival.com/breast1.html.

84. Stoll BA: Eating to beat breast cancer: potential rolefor soy supplements. Ann Oncol, 1997; Mar; 8(3): 223-5.

85. M essina MJ, Loprinzi CL.Soy for breast cancer survivors: a critical review of the literature, J Nutr, 2001, Nov; 131(11): 3095S-108S.

86. Hilakivi-Clarke L, Cho E, deAssis $S$ et al: Maternal and Prepubertal Diet, Mammary Development and Breast Cancer Risk, J Nutr, 2001; 131: 154S-157S.

87. This P, De la Rocheofordiere A, Clough K:
Magdelenat and the Breast Cancer Group of the Institut Curie. Phytoestorgens after breast cancer, Endocrine-related Cancer, (2001); 829-134.

88. Fleming RM , Boyd LB, Kubovy K:The Camel ot Foundation, Omaha, Nebraska, USA.Breast Enhanced Scintigraphy Test (B.E.S.T.) Demonstrates Improvement in Breast Inflammation in Women Consuming Soy Protein. http:// www.revivalsoy.com/breastinflammation.html

89. Burow ME, Boue SM, Collins-Burow BM, et al: Tulane-Xavier Center for Bioenvironment Research, Molecular and Cellular for Biology Program, and Department of Pharmacology (M.E.B., S.L., J.A.M.), Tulane University Medical Center.Phytochemical Glyceollins, I solated from Soy, Mediate Antihormonal Effects through Estrogen Receptor alpha and beta. J Clin Endocrinol Metab, 2001; Apr 1; 86(4): 1750-1758.

90. Shen F. Weber G: Synergistic down-regulation of signal transduction by tamoxifen and genistein in breast cancer cells. Exper Oncol, Indiana U.Sch. M ed., Indianapolis, IN 462025119. 33. 